\title{
Original
}

\section{KISS1 gene analysis in Korean girls with central precocious puberty: a polymorphism, p.P110T, suggested to exert a protective effect}

\author{
Jung Min $\mathrm{Ko}^{1)}$, Hyo Sung Lee ${ }^{2)}$ and Jin Soon Hwang²) \\ 1) Department of Medical Genetics, Ajou University School of Medicine, Suwon, Korea \\ ${ }^{2)}$ Department of Pediatrics, Ajou University School of Medicine, Suwon, Korea
}

\begin{abstract}
Mutations in the GPR54 gene have already been identified as a cause of idiopathic hypogonadotrophic hypogonadism and central precocious puberty (CPP) in certain patients. However, currently there is only a limited amount of data available regarding KISS1 gene mutations or polymorphisms. The aim of this study is to identify KISS1 gene mutations or polymorphisms in Korean girls with CPP. 101 Korean girls with CPP were recruited as the patient group, and 51 healthy Korean female adults as the control group. All coding exons and exon-intron boundaries of the KISS1 gene were sequenced. The relationships between identified sequence variations and CPP were evaluated via the comparison of allele frequencies between the two groups. Different clinical characteristics were also compared between the subgroups with or without a certain variation in the patient group. Eight polymorphisms were identified in the KISS1 gene. Although two of them were novel, those polymorphisms could not lead to amino acid changes. p.P110T was detected less frequently in CPP patients than in the controls $(P=0.022)$. Moreover, the CPP patients with p.P110T evidenced lower peak FSH values under GnRH stimulation than those without p.P110T $(P=0.002)$. The allele frequencies of several polymorphisms in the Korean population were identified in this study. An infrequent polymorphism in the KISS1 gene, p.P110T, appeared to be meaningful. This polymorphism was suggested to exert a protective effect on pubertal precocity, even though more evidence will be required to confirm the accurate function.
\end{abstract}

Key words: Central precocious puberty, KISS1 gene, GPR54 gene, SNP, Polymorphism

PUBERTY is a complex, coordinated biological process with multiple levels of regulation. It is initiated by the secretion of the gonadotropin-releasing hormone (GnRH) from specialized hypothalamic neurons to stimulate hormonal cascades and gonadal activation [1]. The development of the pulsatile release of GnRH secretion mediated through the kisspeptin activation of G-protein coupled receptor-54 (GPR54) appears to be a central event at the onset and during the progression of puberty [2-4]. The stimulation and suppression of influence of the forms of glutamatergic and GABAergic neuronal inputs appears to regulate the timing of this process [5, 6]. As two groups

Received Mar. 9, 2010; Accepted Jun. 18, 2010 as K10E-073 Released online in J-STAGE as advance publication Jul. 10, 2010

Correspondence to: Jin Soon Hwang, M.D., Ph.D., Department of Pediatrics, Ajou University School of Medicine, San 5, Woncheondong, Yeongtong-gu, Suwon 443-721, Korea.

E-mail: pedhwang@ajou.ac.kr around the world discovered simultaneously, in 2003, that inactivating mutations in the GPR54 gene result in idiopathic hypogonadotropic hypogonadism (IHH) in certain patients [2,3], kisspeptin, along with its receptor GPR54, is believed to constitute a critical gatekeeper of sexual maturation, and has been the focus of intense study by investigators. Unlike IHH, central precocious puberty (CPP) is the other extreme of pubertal development. Recently, in 2008, an activating mutation in the GPR54 gene was associated with CPP [7]. The most important function of the kisspeptin/GPR54 system in the process of puberty makes it necessary to investigate the mutations and polymorphisms in the KISS1 gene and their association with CPP, as well as the GPR54 gene. Thus far, only two groups have previously described mutations or polymorphisms of KISS1, the gene encoding for the kisspeptins $[8,9]$. However, further evidence will be necessary to confirm the pathogenicity of these variations, 
Table 1 Primers used in the analysis of the KISS1 gene

\begin{tabular}{lcc}
\hline Primer & Forward (5’ to 3') & Reverse (5' to 3') \\
\hline Exon 2 & TCA GCA CCC AGC CCA GAT CC & TTG CAA CAA CCC ACT TGC TCC C \\
Exon 3 & ATG GGA TGA CAG GAG GTG TTG & ACC ATC CAT TGA GGA TGG AAG \\
\hline
\end{tabular}

because no functional analyses were conducted in these studies.

The KISS1 gene was first discovered in 1996, and has since been mapped to the long arm of chromosome 1q32. This gene consists of three exons, two of which are partially translated exons (exons 2 and 3), which give rise to a 145-amino acid precursor peptide [10]. The precursor peptide is then cleaved to 54 (68121) amino acids in length, which can be truncated further to 14 (108-121), 13 (109-121) or 10 (112-121) amino acid carboxyl-terminal fragments. These fragments, which are referred to as kisspeptins, have subsequently been shown to bind to and activate GPR54 with equal potency [11].

In this study, we evaluated the occurrence of sequence variations, including mutations and single-nucleotide polymorphisms (SNPs), of the KISS1 gene in a cohort of 101 girls with CPP, and attempted to clarify the effect of each sequence variation that differed between the CPP girls and the controls.

\section{Subjects and Methods}

\section{(1) Subjects}

Two groups of subjects were involved in this study. The patient group consisted of 101 Korean girls with idiopathic central precocious puberty (CPP) recruited from the Ajou University Hospital in Suwon, Korea. CPP was diagnosed in accordance with the following criteria: (1) objective breast budding appeared before the age of 8 years, (2) advanced bone age more than 1 year above chronological age, and (3) pubertal LH peak values (cut-off value; $\geq 5 \mathrm{mIU} / \mathrm{mL}$ ) and the $\mathrm{LH} /$ FSH ratios above 1.00 under the gonadotropin releasing hormone $(\mathrm{GnRH})$ stimulation conducted prior to the age of 9 years. The mean age of breast budding and menarche in Korean girls are $11.3 \pm 1.3$ years and $12.3 \pm 1.2$ years, respectively [12]. Then, the age of 8 years proposed in our inclusion criteria of CPP is -2.54 SD away from the mean age of breast budding in Korean girls. Reference value of the LH/FSH ratio in response to GnRH stimulation is $0.89 \pm 0.49$ in Korean pubertal girls [13]. CPP with an identified eti- ology, such as brain tumor or cranial irradiation, was excluded. Bone age was measured via the method developed by Greulich and Pyle [14], and sexual maturity rating (SMR) according to the Tanner staging system was assessed by one pediatric endocrinologist.

The control group consisted of 51 independent healthy Korean women more than 20 years of age, who were recruited as volunteers on the basis of a freewill questionnaire concerning their breast development after the age of 10 years, and menarche after 12 years of age. The mean age of menarche in the study population was $14.19 \pm 1.34$ years, and their height SDS was $-0.42 \pm 0.89$.

The study protocols were reviewed and approved by the Institutional Review Board of the Ajou University Hospital, and written informed consent was obtained from all subjects, or from their parents.

\section{(2) The KISS1 gene analysis}

Genomic DNA was isolated from the peripheral blood leukocytes of the study subjects using a DNA isolation kit (QIAGEN; GmbH, Helden, Germany). All coding exons (exon 2 and 3) and the intronic flanking regions of the KISS1 gene were PCR amplified with four pairs of specific primers (Table 1). Amplifications were conducted over 30 cycles, and each cycle consisted of denaturation at $94^{\circ} \mathrm{C}$ for 30 sec, annealing at $68^{\circ} \mathrm{C}$ (exon 2) or $63^{\circ} \mathrm{C}$ (exon 3) for $30 \mathrm{sec}$, and extension at $72^{\circ} \mathrm{C}$ for $30 \mathrm{sec}$. Additional extension at $72^{\circ} \mathrm{C}$ for $10 \mathrm{~min}$ after last amplification cycle. PCR was performed in a reaction volume of $20 \mu \mathrm{L}$ containing $100 \mathrm{ng}$ of genomic DNA template, $1 \mu \mathrm{M}$ of each primer, $10 \mathrm{mM}$ of each dNTP, $25 \mathrm{mM}$ $\mathrm{MgCl}_{2}, 100 \mathrm{mM} \mathrm{KCl}, 20 \mathrm{mM}$ Tris-HCl (pH 8.3), and $1 \mathrm{U}$ of Taq DNA polymerase (Takara Bio Inc.; Shiga, Japan). After amplification, PCR mixtures were separated on $1.5 \%$ agarose gels with ethidium bromide to confirm the size and purity of the PCR products.

Subsequently, DNA sequencing reactions were conducted using the same primer pairs and a BigDye Terminator V3.1 Cycle Sequencing kit (Applied Biosystems; Foster City, CA) in accordance with the manufacturer's instructions. The sequencing reaction 
mixtures were electrophoresed and analyzed using an ABI3130xl Genetic Analyzer (Applied Biosystems) and Sequencing Analysis v.5.2 software.

\section{(3) Hormonal studies}

The GnRH stimulation test was conducted to evaluate the pubertal status in all patients. Basal serum samples were obtained prior to GnRH injection, and poststimulation samples were acquired $30,45,60$, and 90 min after injection for measurements of LH and FSH levels. The hormonal levels were measured via immunoradiometric assays (BioSource, Nivelles, Belgium). LH and FSH levels and the LH/FSH ratio were compared to previously documented age-related reference values [15].

\section{(4) Statistical analysis}

The allele frequencies were compared between the patient and control groups. Deviations from HardyWeinberg equilibrium were also evaluated via the comparison of observed and expected genotype frequencies. When the significant difference of allele frequencies between the patient and the control groups was noted for each polymorphism, the clinical characteristics and results of the hormonal study were also compared between patients harboring a certain polymorphism (homozygote or heterozygote) and those lacking that polymorphism.

The SPSS 12.0 software package (SPSS Inc.; Chicago, IL) was used to perform statistical analyses, and the data were expressed as the means \pm SD or the SDS. Fisher's exact test and Mann-Whitney U test were used for data analysis, and $P$ values of $<0.05$ were considered statistically significant.

\section{Results}

\section{(1) Clinical characteristics and results of GnRH stimulation test in CPP patients}

In the patient group, the mean age at diagnosis was $7.93 \pm 0.98$ years, and breast budding was first observed at a mean age of $7.09 \pm 1.14$ years. The bone age at diagnosis was $10.24 \pm 1.38$ years, and the mean discrepancy with the chronological age was $2.31 \pm 0.40$ years. The mean SMR stage at diagnosis was $2.45 \pm$ 0.73 for breast development and $1.14 \pm 0.45$ for pubic hair development. Height and weight at diagnosis was $1.22 \pm 0.95$ and $0.96 \pm 0.84$ SDS respectively, and patients' heights were higher than their mid-parental
Table 2 Baseline clinical characteristics and results of GnRH stimulation test in patients with CPP

\begin{tabular}{lc}
\hline Auxological parameters & Patients $(\mathrm{n}=101)$ \\
\hline CA at breast budding (year) & $7.39 \pm 1.08$ \\
CA at diagnosis (year) & $7.93 \pm 0.98$ \\
BA - CA at diagnosis (year) & $2.85 \pm 0.40$ \\
Weight at diagnosis (SDS) & $0.96 \pm 0.84$ \\
Height at diagnosis (SDS) & $1.22 \pm 0.95$ \\
BMI at diagnosis (SDS) & $0.58 \pm 0.85$ \\
MPH (SDS) & $-0.50 \pm 1.00$ \\
Height - MPH (SDS) & $1.72 \pm 0.92$ \\
Birth weight (SDS) & $-0.40 \pm 1.00$ \\
Breast SMR (stage) & $2.45 \pm 0.73$ \\
Pubic hair SMR (stage) & $1.14 \pm 0.45$ \\
\hline Basal LH (mIU/mL) & $2.20 \pm 0.94$ \\
Peak LH (mIU/mL) & $17.64 \pm 14.46$ \\
Basal FSH (mIU/mL) & $2.70 \pm 1.52$ \\
Peak FSH (mIU/mL) & $12.48 \pm 4.77$ \\
Peak/basal LH ratio & $9.78 \pm 10.90$ \\
Peak LH/FSH ratio & $1.49 \pm 1.12$ \\
\hline
\end{tabular}

CA: chronological age, BA: bone age, BA - CA: bone age advancement, MPH: mid-parental height

height $(-0.50 \pm 1.00)$ as the genetic target.

According to the results of the GnRH stimulation test, the basal and the peak LH values were $2.20 \pm 0.94$ $\mathrm{mIU} / \mathrm{mL}$ (reference range; $0.01-0.21 \mathrm{mIU} / \mathrm{mL}$ ) and $17.64 \pm 14.46 \mathrm{mIU} / \mathrm{mL}$, respectively. The basal (reference range; $0.50-2.41 \mathrm{mIU} / \mathrm{mL}$ ) and peak FSH values were $2.70 \pm 1.52 \mathrm{mIU} / \mathrm{mL}$ and $12.48 \pm 4.77 \mathrm{mIU} /$ $\mathrm{mL}$ respectively, and the peak/basal LH ratio and peak $\mathrm{LH} / \mathrm{FSH}$ ratio were $9.78 \pm 10.90$ and $1.49 \pm 1.12$, respectively.

The baseline clinical characteristics and results of the GnRH stimulation tests in the patient group are summarized in Table 2.

\section{(2) Identified polymorphisms in the KISS1 gene analysis}

Direct sequencing of the KISS1 gene revealed eight polymorphisms as shown in Fig.1 and listed in Table 3. Among the 8 polymorphisms detected in this study, six have been previously reported, whereas the other two were novel polymorphisms (54650098 G/A and $54649892 \mathrm{C} / \mathrm{GT}$ ). One of the known polymorphisms, $54650055 \mathrm{G} / \mathrm{T}$, was initially identified in Chinese CPP patients in 2007 [8], and was nonsynonymous, result- 
(a)

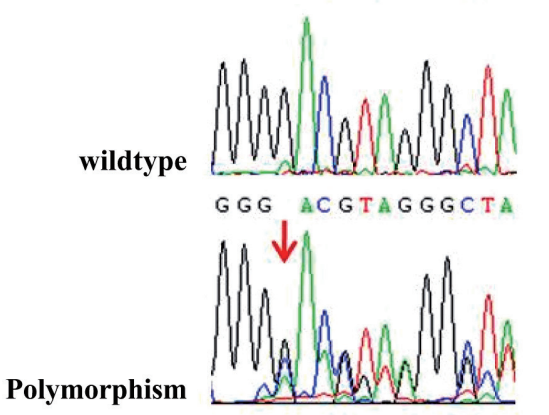

(b) G G G G G G G G G C G G

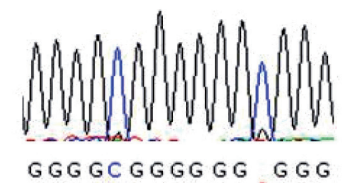

GGG GCGGGG G G GG

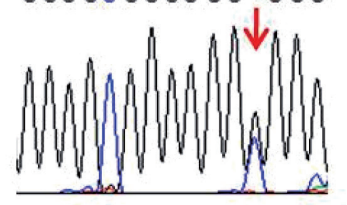

c) $\mathrm{CGGGGCGGGGG}$

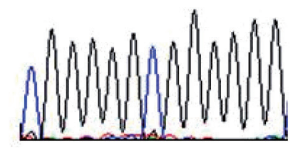

C GGGGGCGGGGTGG

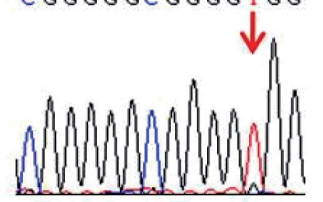

(d)

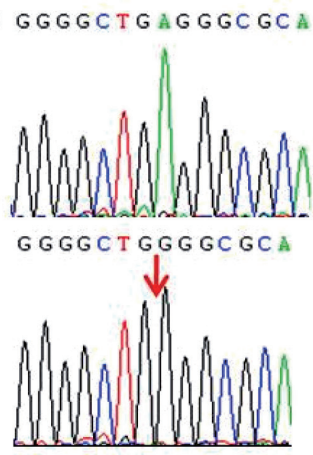

Polymorphism

(e) $\triangle$ G A ACT TCCGA ACT

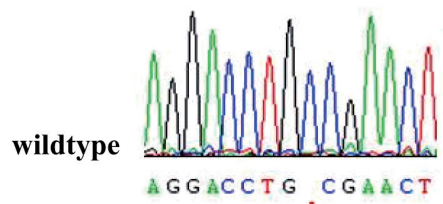

$\downarrow$

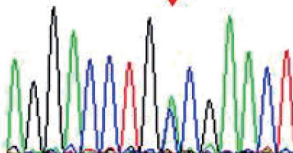

(f) GATCCCGCACCCA
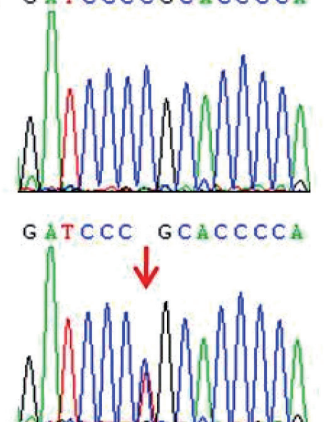

(g) GGGAGCCCCAGCA

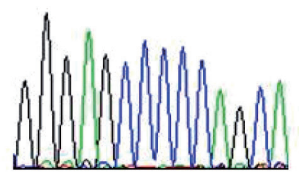

G GG AGCCGCCAGCA

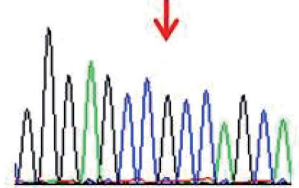

(h) T TTGGGGAGCCAT T

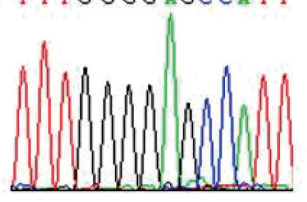

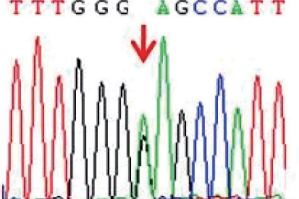

Fig. 1 Partial sequences of the KISS1 gene show the polymorphisms detected in the present study. (a) a heterozygote of g.54649892C>G; g.54649892_54649893insT (c.*74G>C;;c.74_*75insA), (b) a heterozygote of g.54649896G>C (c.*70C>G), (c) a homozygote of g.54649898insA (c.*67_*68insT), (d) a homozygote of g.54649966delT (c.417delA), (e) a heterozygote of g.54650055G > T (c.328C >A), (f) a heterozygote of g.54650098G > A (c.285C > T), (g) a homozygote of g.54650141G >C $(\mathrm{c} .242 \mathrm{C}>\mathrm{G})$, (h) a heterozygote of g.54652301C $>\mathrm{T}(\mathrm{c} .58 \mathrm{G}>\mathrm{A})$. The positions of the polymorphisms are defined according to contig NM_002256.3 in this figure.

Table 3 The KISS1 gene polymorphisms identified by sequencing $(\mathrm{n}=152)$

\begin{tabular}{|c|c|c|c|c|c|c|c|c|}
\hline No. & Polymorphism & Location & $\begin{array}{l}\text { mRNA } \\
\text { position }\end{array}$ & dbSNP ID & $\begin{array}{l}\text { Frequency } \\
\text { in samples }\end{array}$ & Function & $\begin{array}{c}\text { AA } \\
\text { position }\end{array}$ & \\
\hline 1 & $\begin{array}{c}\text { g.54649892C>G; } \\
\text { g.54649892_54649893insT } \\
\text { bc.*74G>C;c.*74_*75insAb }\end{array}$ & Exon 3 & 645 & - & $0.974 / 0.026$ & 3’UTR & - & novel \\
\hline 2 & $\begin{array}{c}\text { g. } 54649896 \mathrm{G}>\mathrm{C} \\
\text { c. } * 70 \mathrm{C}>\mathrm{G}\end{array}$ & Exon 3 & 641 & rs1132506 & $0.536 / 0.464$ & 3’UTR & - & \\
\hline 3 & $\begin{array}{l}\text { g.54649898insA } \\
\text { c. }{ }^{* 67}{ }^{*} 68 \text { ins T }\end{array}$ & Exon 3 & 638 & rs35128240 & $0.553 / 0.447$ & 3’UTR & - & \\
\hline 4 & $\begin{array}{l}\text { g.54649966delT } \\
\text { c. } 417 \text { delA }\end{array}$ & Exon 3 & 571 & rs71745629 & $0.553 / 0.447$ & frameshift & 139 & p.X139fx \\
\hline 5 & $\begin{array}{l}\text { g. } 54650055 \mathrm{G}>\mathrm{T} \\
\text { c. } 328 \mathrm{C}>\mathrm{A}\end{array}$ & Exon 3 & 482 & - & $0.954 / 0.046$ & missense & 110 & p.P110T \\
\hline 6 & $\begin{array}{c}\text { g. } 54650098 \mathrm{G}>\mathrm{A} \\
\text { c. } 285 \mathrm{C}>\mathrm{T}\end{array}$ & Exon 3 & 439 & - & 0.993/0.007 & missense & 95 & $\begin{array}{c}\text { novel, } \\
\text { synonymous }\end{array}$ \\
\hline 7 & $\begin{array}{l}\text { g. } 54650141 G>C \\
\text { c. } 242 C>G\end{array}$ & Exon 3 & 396 & rs4889 & $0.553 / 0.447$ & missense & 81 & p.P81R \\
\hline 8 & $\begin{array}{c}\text { g. } 54652301 \mathrm{C}>\mathrm{T} \\
\text { c. } 58 \mathrm{G}>\mathrm{A}\end{array}$ & Exon 2 & 212 & rs12998 & $0.970 / 0.030$ & missense & 20 & p.E20K \\
\hline
\end{tabular}

AA: amino acid

The positions of the polymorphisms are defined according to contig NT_004487.18 for genomic DNA ${ }^{\mathrm{a}}$ and NM_002256.3 for cDNA ${ }^{\mathrm{b}}$. 
Table 4 Allele and genotype frequencies of the KISS1 polymorphisms from 100 patients and 51 controls

\begin{tabular}{|c|c|c|c|c|c|c|c|c|c|c|c|c|}
\hline \multirow[b]{2}{*}{ Polymorphism } & \multirow[b]{2}{*}{ Group } & \multicolumn{4}{|c|}{ Allele frequency } & \multicolumn{6}{|c|}{ Genotype frequency } & \multirow[b]{2}{*}{${ }^{*} P$-value } \\
\hline & & \multicolumn{2}{|c|}{1} & \multicolumn{2}{|c|}{2} & \multicolumn{2}{|c|}{11} & \multicolumn{2}{|c|}{12} & \multicolumn{2}{|c|}{22} & \\
\hline 54649892 C/GT & Patient & 97 & 0.985 & 3 & 0.015 & 97 & 0.970 & 3 & 0.030 & 0 & 0.000 & 0.120 \\
\hline $\mathrm{C}=1 ; \mathrm{GT}=2$ & Control & 97 & 0.951 & 5 & 0.049 & 46 & 0.902 & 5 & 0.098 & 0 & 0.000 & \\
\hline 54649896 G/C & Patient & 103 & 0.515 & 97 & 0.485 & 26 & 0.260 & 51 & 0.510 & 23 & 0.230 & 0.571 \\
\hline $\mathrm{G}=1 ; \mathrm{C}=2$ & Control & 59 & 0.578 & 43 & 0.422 & 17 & 0.333 & 25 & 0.490 & 9 & 0.176 & \\
\hline 54649898 -/A & Patient & 105 & 0.525 & 95 & 0.475 & 28 & 0.280 & 49 & 0.490 & 23 & 0.230 & 0.371 \\
\hline Wild=1; Ins A=2 & Control & 62 & 0.608 & 40 & 0.392 & 20 & 0.392 & 22 & 0.431 & 9 & 0.176 & \\
\hline 54649966 T/- & Patient & 105 & 0.525 & 95 & 0.475 & 28 & 0.280 & 49 & 0.490 & 23 & 0.230 & 0.371 \\
\hline Wild=1; Del T=2 & Control & 62 & 0.608 & 40 & 0.392 & 20 & 0.392 & 22 & 0.431 & 9 & 0.176 & \\
\hline 54650055 G/T & Patient & 194 & 0.970 & 6 & 0.030 & 95 & 0.950 & 4 & 0.040 & 1 & 0.010 & 0.022 \\
\hline $\mathrm{G}=1 ; \mathrm{T}=2$ & Control & 94 & 0.922 & 8 & 0.078 & 43 & 0.843 & 8 & 0.157 & 0 & 0.000 & \\
\hline 54650098 G/A & Patient & 198 & 0.990 & 2 & 0.010 & 98 & 0.980 & 2 & 0.020 & 0 & 0.000 & 0.550 \\
\hline $\mathrm{G}=1 ; \mathrm{A}=2$ & Control & 102 & 1.000 & 0 & 0.000 & 51 & 1.000 & 0 & 0.000 & 0 & 0.000 & \\
\hline 54650141 G/C & Patient & 105 & 0.525 & 95 & 0.475 & 28 & 0.280 & 49 & 0.490 & 23 & 0.230 & 0.371 \\
\hline $\mathrm{G}=1 ; \mathrm{C}=2$ & Control & 62 & 0.608 & 40 & 0.392 & 20 & 0.392 & 22 & 0.431 & 9 & 0.176 & \\
\hline $54652301 \mathrm{C} / \mathrm{T}$ & Patient & 199 & 0.985 & 3 & 0.015 & 98 & 0.970 & 3 & 0.003 & 0 & 0.000 & 0.061 \\
\hline $\mathrm{C}=1 ; \mathrm{T}=2$ & Control & 96 & 0.941 & 6 & 0.059 & 45 & 0.882 & 6 & 0.118 & 0 & 0.000 & \\
\hline
\end{tabular}

* Comparison of the allele frequencies between the patient group and the control group

ing in the substitution of p.P110T. Additionally, there were another two nonsynonymous SNPs (54652301 $\mathrm{C} / \mathrm{T}$ and $54650141 \mathrm{G} / \mathrm{C}$ ), which induced substitutions of p.E20K and p.P81R, respectively. From two novel polymorphisms, 54650098 G/A was synonymous and 54649892 C/GT was located in 3'UTR. Seven of eight polymorphisms were identified in both the patient and control groups, and the results fitted HardyWeinberg equilibrium expectations. Although one novel SNP (54650098 G/A) was detected only in the patient group, it induced a synonymous change and did not appear to affect the activity of the kisspeptins. Regardless of the phenotype group, the most frequent polymorphism was $54649896 \mathrm{G} / \mathrm{C}(46.4 \%)$, and the other three common SNPs (54650141 G/C, 54649966 T/-, and 54649898 -/A) were always found together with the same allele frequency of $44.7 \%$. All patients with $54649892 \mathrm{C} / \mathrm{GT}$, without exception, harbor 54649896 G/C.

Allele counts and frequencies in the two groups are shown in Table 4. Using Fisher's exact test, the associations between the polymorphisms and the two phenotype groups were evaluated. Among the polymorphisms, only $54650055 \mathrm{G} / \mathrm{T}$ was detected statistically significantly less frequently in the patient group $(P=$ 0.022). Although $54652301 \mathrm{C} / \mathrm{T}$ was also detected less frequently in the patient group, this was not a sta- tistically significant difference $(P=0.061)$, and no differences in the frequencies of the other six polymorphisms were noted to exist between the two groups.

\section{(3) Clinical significance of 54650055 G/T (p.P110T) in patients with $\mathrm{CPP}$}

Based on the finding that $54650055 \mathrm{G} / \mathrm{T}$ was detected less frequently in the patient group $(P=0.022)$, we compared the clinical characteristics and hormone values between the two subgroups (the subgroup with $54650055 \mathrm{G} / \mathrm{G}$, and the subgroup with $\mathrm{G} / \mathrm{T}$ or $\mathrm{T} / \mathrm{T}$ ). Patients with heterozygous (G/T) and homozygous (T/ T) sequence changes were classified to the same statistical analysis subgroup, as only one patient evidenced homozygous sequence changes at 54650055 . Under GnRH stimulation conditions, the subgroup with $54650055 \mathrm{G} / \mathrm{T}$ or $\mathrm{T} / \mathrm{T}$ evidenced a significantly lower level of peak FSH $(P=0.002)$ and a tendency to have a lower peak $\mathrm{LH}$ value $(P=0.121)$ than the subgroup with G/G. Basal hormone levels, the LH/FSH ratio, and the auxological parameters at diagnosis--including height, weight, BMI, MPH, birth weight, SMR, and bone age advancement--did not differ between the two subgroups in CPP patients. The results are shown, in detail, in Table 5.

Although $54652301 \mathrm{C} / \mathrm{T}$ was also less frequently identified in the patient group $(P=0.061)$, we noted 
Table 5 Clinical significance of $54650055 \mathrm{G} / \mathrm{T}$ (p.P110T) in patients with CPP

\begin{tabular}{lccc}
\hline Subgroup with & $54650055 \mathrm{G} / \mathrm{G}(\mathrm{n}=95)$ & $54650055 \mathrm{G} / \mathrm{T}$ or T/T $(\mathrm{n}=5)$ & $P$ value \\
\hline CA at breast budding (year) & $7.39 \pm 1.10$ & $7.39 \pm 0.32$ & 0.50 \\
CA (year) & $7.90 \pm 1.00$ & $8.18 \pm 0.40$ & 0.66 \\
BA - CA (year) & $2.91 \pm 1.19$ & $2.94 \pm 1.17$ & 0.88 \\
Weight at diagnosis (SDS) & $0.95 \pm 0.85$ & $0.74 \pm 0.68$ & 0.50 \\
Height at diagnosis (SDS) & $1.19 \pm 0.96$ & $1.35 \pm 0.78$ & 0.67 \\
BMI at diagnosis (SDS) & $0.56 \pm 0.85$ & $0.54 \pm 0.81$ & 0.93 \\
MPH (SDS) & $-0.54 \pm 0.94$ & $0.02 \pm 1.24$ & 0.37 \\
Height - MPH (SDS) & $1.74 \pm 0.93$ & $1.33 \pm 0.71$ & 0.28 \\
Birth weight (SDS) & $-0.46 \pm 1.05$ & $-0.43 \pm 1.21$ & 0.99 \\
Breast SMR (stage) & $2.46 \pm 0.75$ & $2.20 \pm 0.45$ & 0.58 \\
Pubic hair SMR (stage) & $1.13 \pm 0.45$ & $1.20 \pm 0.45$ & 1.00 \\
\hline Basal LH (mIU/mL) & $2.24 \pm 0.93$ & $2.30 \pm 1.04$ & 0.87 \\
Peak LH (mIU/mL) & $18.12 \pm 14.90$ & $10.54 \pm 6.18$ & 0.12 \\
Basal FSH (mIU/mL) & $2.76 \pm 1.47$ & $2.70 \pm 1.62$ & 0.26 \\
Peak FSH (mIU/mL) & $12.79 \pm 4.75$ & $7.12 \pm 1.84$ & 0.002 \\
Peak/basal LH ratio & $9.86 \pm 11.20$ & $8.60 \pm 8.18$ & 0.65 \\
Peak LH/FSH ratio & $1.50 \pm 1.17$ & $1.49 \pm 0.71$ & 0.47
\end{tabular}

CA: chronological age, BA: bone age, BA - CA: bone age advancement, MPH: mid-parental height

no differences in any of the compared variables, including the hormonal values.

\section{Discussion}

Normal pubertal development in girls follows an ordered sequence for breast and pubic hair development, beginning with thelarche or adrenarche and progressing according to the description of Tanner [16]. The physical manifestations of puberty result from a complex series of physiological events. However, the onset of puberty occurs across a wide range of ages, even in normal girls. Genetic regulation can be studied by examining children who develop puberty at the extremes of the normal variation, at or in excess of 2 SD from the mean for the population [17]. In these situations of either precocious or delayed puberty, a number of genes may affect pubertal timing and the tempo of puberty. Researchers are currently continuing to elucidate the underlying molecular mechanisms that trigger pubertal onset and modulate the hormonal cascades inherent to puberty.

Kisspeptin was initially demonstrated, in 2003, to perform a function in the reproductive axis, wherein mutations in the GPR54 gene result in idiopathic hy- pogonadotrophic hypogonadism [2, 3]. The discovery of these mutations suggested that the GPR54 receptor and its ligand kisspeptins are crucial regulators of puberty and the hypothalamus-pituitary-gonadal axis. Since 2003, further mutations of the GPR54 have been demonstrated to cause idiopathic hypogonadotrophic hypogonadism [4, 18, 19], and an activating mutation leading to CPP was identified in 2008 [7]. However, no definite causative mutation has been detected in another promising candidate gene, KISS1, in humans with idiopathic hypogonadotrophic hypogonadism or CPP. Recently, KISS1 knockout mouse models have been developed and have been shown to evidence, to varying degrees, characteristics of idiopathic hypogonadotrophic hypogonadism [20, 21], whereas GPR54 knockout mice consistently evidence characteristics of hypogonadotrophic hypogonadism [3, 20]. The lesscomplete phenotype detected in the KISS1 knockout mice suggested that other peptide ligands may be capable of compensating for kisspeptins and activating GPR54 [22].

The eight polymorphisms were detected via the sequencing of the KISS1 gene, and the frequencies of each polymorphism were calculated and compared between the patient and control groups; each poly- 
morphism was also genotyped. According to the calculated statistical results, the nonsynonymous SNP $54650055 \mathrm{G} / \mathrm{T}$, in which the 110th amino acid of KISS1 protein was substituted from proline to threonine (p.P110T) was found to be statistically meaningful. Although p.P110T was identified in both the patients and the controls, the allele frequencies of these groups differed statistically. The control group evidenced a significantly higher frequency of p.P110T than the patient group, with allele frequencies of 0.078 and 0.030 , respectively.

This SNP was first reported in a study of Chinese CPP patients in 2007 [8], and they demonstrated that p.P110T was an infrequent polymorphism with an allele frequency of 0.057 in all sequenced subjects. This allele frequency was quite similar to that of the Korean population assessed in our study, in which the allele frequency was calculated as 0.046. Moreover, p.P110T was detected statistically significantly more commonly in the Chinese controls than in the CPP patients, and this finding was also consistent with the findings of our study. Additionally, in the preceding study from China [8], p.P110T was not detected in the group of normal African female adults, and it has already been suggested that p.P110T might exert some protective effects on pubertal precocity, judging from the fact that African-American children reached their pubertal milestones earlier than other racial groups [23]. Considering that the p.P110 site is contained by the three natural in vivo forms of kisspeptin, kisspeptin-54, 14, and 13, our result consistently supports the hypothesis that p.P110T may alter the function of kisspeptins and can exert certain effects against the rapid progression of puberty. However, this has yet to be confirmed by functional studies, and more evidence will be necessary to confirm that this substitution alters the activity of kisspeptins.

Among the other polymorphisms, a novel SNP (54650098 G/A) did not result in any amino acid change, and two other nonsynonymous SNPs (p.E20K and p.P81R) did not exhibit a significant relationship in either the patient or the control groups. This polymorphism introduced a substitution at position 20 from glutamate to lysine, which was not noted in all types of kisspeptins. Additionally, a substitution occurred at the 81st site from proline to arginine, which was observed in kisspeptin-54 but not in the other three forms. p.P81R also would not seriously influence the bioactivity of kisspeptins, and this supposition was supported by the results of a previous study showing that kisspeptin-54 was unstable and could readily degrade into kisspeptin-14, 13, and 10 [11]. Thus, kisspeptin-14, 13, and 10 might be more important than kisspeptin-54.

We also noted that three frequently detected SNPs (54650141 G/C, 54649966 T/-, and 54649898 -/A) were always found together in groups. This finding has yet to be reported. In the previous Chinese study [8], two SNP2 were detected in exon 3 of the KISS1 gene, and only $54650141 \mathrm{G} / \mathrm{C}$ was identified to be a gene commonly shared with Koreans. The genetic background of these two ethnic groups appeared to differ profoundly, even though Koreans and Chinese are both ethnically Asians.

Puberty begins when the hypothalamic GnRH neurons secrete GnRH in a pulsatile manner. Pulsatile GnRH causes pituitary gonadotropins to release $\mathrm{LH}$ and FSH. LH induces the production of androstenedione in ovarian thecal cells, whereas FSH causes the aromatase enzyme in follicular cells to synthesize estradiol. The increase in serum estradiol causes breast tissue to enlarge and become palpable [24]. At the time at which breast budding occurs, LH peak amplitude increases by approximately 10 -fold and the FSH peak amplitude doubles. As puberty progresses, the LH pulse amplitude increases markedly, up to 2040 fold from prepubertal levels during sleep [25, 26]. We diagnosed CPP only in cases in which the GnRHstimulated LH peak values were in excess of $5 \mathrm{mIU} /$ $\mathrm{mL}$, although the basal LH elevation analyzed by new assay methods has been also confirmed as another reliable method for the diagnosis of CPP [27].

In order to evaluate the clinical significance of p.P110T, we compared the clinical characteristics and hormone values between the subgroups with or without this SNP in the patient group. Under GnRH stimulation conditions, the subgroup with p.P110T $(54652301 \mathrm{C} / \mathrm{T}$ or $\mathrm{T} / \mathrm{T})$ evidenced a significant reduction in peak FSH $(P=0.002)$ and a more moderate reduction in peak LH value $(P=0.121)$ as compared to the wild-type subgroup (54652301 C/C). These hormonal findings also support our hypothesis that p.P110T could play a protective role against the rapid progression of puberty. It has been demonstrated that the $\mathrm{LH}$ response to $\mathrm{GnRH}$ stimulation is diagnostically more helpful than FSH, and the FSH response in pubertal children shows a wide normal range and overlaps, largely, with that in prepubertal children [27, 28]. 
However, a significant reduction in the concentration of basal FSH concentration and a relatively moderate reduction in basal LH level were also noted in studies conducted with GPR54 and KISS1 knockout mice [3, 20]. Although the underlying mechanisms relevant to these findings have yet to be elucidated, the FSH concentration might be more sensitively affected by the Kisspeptin/GPR54 system. Considering that p.P110T is just another type of SNP, it cannot be authoritatively stated that these FSH and LH changes observed under GnRH stimulation were meaningless.
In conclusion, we have attempted to identify sequence variations of the KISS1 gene associated with CPP in Korean girls, and have noted some possibilities that a certain SNP within the KISS1 gene might function as a modulating factor in the onset and progression of puberty. A possible limitation of the present study was that the sample scale was relatively small, and that a $P$-value of 0.022 was not sufficiently significant. Therefore, the association between p.P110T and CPP should be validated by further evidence obtained from functional studies.

\section{References}

1. Wildt L, Marshall G, Knobil E (1980) Experimental induction of puberty in the infantile female rhesus monkey. Science 207: 1373-1375.

2. de Roux N, Genin E, Carel JC, Matsuda F, Chaussain JL, Milgrom E (2003) Hypogonadotropic hypogonadism due to loss of function of the KiSS1-derived peptide receptor GPR54. Proc Natl Acad Sci U S A 100: 10972-10976.

3. Seminara SB, Messager S, Chatzidaki EE, Thresher RR, Acierno JS, Jr., Shagoury JK, et al. (2003) The GPR54 gene as a regulator of puberty. $N$ Engl $J$ Med 349: 1614-1627.

4. Semple RK, Achermann JC, Ellery J, Farooqi IS, Karet FE, Stanhope RG, et al. (2005) Two novel missense mutations in g protein-coupled receptor 54 in a patient with hypogonadotropic hypogonadism. J Clin Endocrinol Metab 90: 1849-1855.

5. Parent AS, Matagne V, Bourguignon JP (2005) Control of puberty by excitatory amino acid neurotransmitters and its clinical implications. Endocrine 28: 281-286.

6. Mitsushima D, Hei DL, Terasawa E (1994) gammaAminobutyric acid is an inhibitory neurotransmitter restricting the release of luteinizing hormone-releasing hormone before the onset of puberty. Proc Natl Acad Sci U S A 91: 395-399.

7. Teles MG, Bianco SD, Brito VN, Trarbach EB, Kuohung W, Xu S, et al. (2008) A GPR54-activating mutation in a patient with central precocious puberty. $N$ Engl J Med 358: 709-715.

8. Luan X, Zhou Y, Wang W, Yu H, Li P, Gan X, et al. (2007) Association study of the polymorphisms in the KISS1 gene with central precocious puberty in Chinese girls. Eur J Endocrinol 157: 113-118.

9. Silveira LF, Brito VN, Costa EMF, Trarbach EB, Teles M, Mendonca BB, et al. (2006) A novel missense mutation of KISS1 gene in a boy with idiopathic gonadotropin-dependent precocious puberty. Program of $88^{\text {th }}$ Scientific Sessions of the Endocrine Society, OR12-5
(Abstract).

10. West A, Vojta PJ, Welch DR, Weissman BE (1998) Chromosome localization and genomic structure of the KiSS-1 metastasis suppressor gene (KISS1). Genomics 54: 145-148.

11. Kotani M, Detheux M, Vandenbogaerde A, Communi D, Vanderwinden JM, Le Poul E, et al. (2001) The metastasis suppressor gene KiSS-1 encodes kisspeptins, the natural ligands of the orphan $\mathrm{G}$ protein-coupled receptor GPR54. J Biol Chem 276: 34631-34636.

12. Park MJ, Lee IS, Shin EK, Jeong H, Cho SI (2006) The timing of sexual maturation and secular trends of menarchial age in Korean adolescents. Korean J Pediatr 49: 610-616.

13. Choi JY, Kang HJ, Cho WK, Cho KS, Park SH, Hahn $\mathrm{SH}$, et al. (2009) Analysis of gonadotropin-releasing hormone $(\mathrm{GnRH})$ test results in girls with precocious puberty. Korean J Pediatr 52: 1377-1382.

14. Greulich WW, Pyle SI (1953) Radiologic atlas of skeletal development of the hand and wrist. Stanford University Press, Palo alto: 126-183.

15. Nicholson JF, Pesce MA (2004) Laboratory Medicine, Drug Therapy, and Reference Tables. 17th ed. Behrman RE, Kligman RM, Jenson HB, editors. Saunders, Philadelphia: 2396-2427.

16. Tanner JM (1952) The assessment of growth and development in children. Arch Dis Child 27: 10-33.

17. Palmert MR, Boepple PA (2001) Variation in the timing of puberty: clinical spectrum and genetic investigation. J Clin Endocrinol Metab 86: 2364-2368.

18. Lanfranco F, Gromoll J, von Eckardstein S, Herding EM, Nieschlag E, Simoni M (2005) Role of sequence variations of the GnRH receptor and $G$ protein-coupled receptor 54 gene in male idiopathic hypogonadotropic hypogonadism. Eur J Endocrinol 153: 845-852.

19. Tenenbaum-Rakover $\mathrm{Y}$, Commenges-Ducos M, Iovane A, Aumas C, Admoni O, de Roux N (2007) Neuroendocrine phenotype analysis in five patients 
with isolated hypogonadotropic hypogonadism due to a L102P inactivating mutation of GPR54. J Clin Endocrinol Metab 92: 1137-1144.

20. Lapatto R, Pallais JC, Zhang D, Chan YM, Mahan A, Cerrato F, et al. (2007) Kiss1-/- mice exhibit more variable hypogonadism than Gpr54-/- mice. Endocrinology 148: 4927-4936.

21. d'Anglemont de Tassigny X, Fagg LA, Dixon JP, Day K, Leitch HG, Hendrick AG, et al. (2007) Hypogonadotropic hypogonadism in mice lacking a functional Kiss1 gene. Proc Natl Acad Sci U S A 104: 10714-10719.

22. Roseweir AK, Millar RP (2009) The role of kisspeptin in the control of gonadotrophin secretion. Hum Reprod Update 15: 203-212.

23. Herman-Giddens ME (2006) Recent data on pubertal milestones in United States children: the secular trend toward earlier development. Int J Androl 29: 241-246; discussion 286-290.

24. DiVall SA, Radovick S (2009) Endocrinology of female puberty. Curr Opin Endocrinol Diabetes Obes 16: $1-4$
25. Apter D, Butzow TL, Laughlin GA, Yen SS (1993) Gonadotropin-releasing hormone pulse generator activity during pubertal transition in girls: pulsatile and diurnal patterns of circulating gonadotropins. J Clin Endocrinol Metab 76: 940-949.

26. Mitamura R, Yano K, Suzuki N, Ito Y, Makita Y, Okuno A (2000) Diurnal rhythms of luteinizing hormone, follicle-stimulating hormone, testosterone, and estradiol secretion before the onset of female puberty in short children. J Clin Endocrinol Metab 85: 10741080.

27. Resende EA, Lara BH, Reis JD, Ferreira BP, Pereira GA, Borges MF (2007) Assessment of basal and gonadotropin-releasing hormone-stimulated gonadotropins by immunochemiluminometric and immunofluorometric assays in normal children. J Clin Endocrinol Metab 92: 1424-1429.

28. Brito VN, Batista MC, Borges MF, Latronico AC, Kohek MB, Thirone AC, et al. (1999) Diagnostic value of fluorometric assays in the evaluation of precocious puberty. J Clin Endocrinol Metab 84: 3539-3544. 